\title{
El cerdo. Historia de un elemento esencial de la cultura castellana en la conquista y colonización de América (siglo XVI)
}

Justo L. del Río Moreno

Universidad de Cádiz

\begin{abstract}
El cerdo ibérico fue uno de los principales representantes de una cultura, la castellana, eminentemente ganadera. En la conquista y colonización de América tuvo un papel básico en la nutrición, siendo su adaptación al medio la principal garantía de supervivencia para soldados y colonos. Con el avance de la colonización, la crianza se vinculó al tributo indio, prosperando con tal prodigalidad que no tardó en perder protagonismo frente a otros ramos pecuarios con mayores expectativas comerciales, si bien los diferentes productos porcinos tuvieron siempre una gran aceptación en los mercados locales, especialmente en los indígenas.
\end{abstract}

La introducción en América del ganado europeo puede decirse que fue el primer eslabón de una compleja historia, marcada por la confrontación de dos culturas que con el transcurrir del tiempo se mezclarían en una combinación de múltiples simbiosis — no exentas de ciertas imposiciones, conflictos y traumas- que condicionan la propia evolución americana e, incluso, justifican la idiosincrasia actual de países y estados tan ganaderos como Argentina al sur o Texas al norte.

El impacto que provocaron las nuevas especies animales entre la población indígena fue tan tremendo que los europeos no dudaron en aprovechar para sus propósitos el miedo o el asombro con que las recibieron aquéllos. Con el tiempo, del impacto se pasó a la asimilación, constituyendo la ganadería un importante pilar económico, que llegó a configurar también una serie de tipos sociales asociados a su explotación.

La novedad del proceso y la necesidad de realizar comprobaciones, experimentar, aprender y legislar nuevas situaciones dieron lugar a una abundante documentación escrita y pictórica que ilustra en la actualidad cómo se desenvolvieron los animales y qué prácticas se empleaban para su cuidado y explotación.

Tal y como denotan las fuentes documentales e, incluso, describen las fuentes escritas, el desarrollo pecuario no fue igual de homogéneo en toda la América española, surgiendo importantes diferencias entre distintas 
gobernaciones y territorios en función de sus propias particularidades espaciales, ya fueran geográficas, climáticas o poblacionales.

Del mismo modo, aparecieron diferencias en virtud del tiempo histórico en el que se configuraron las distintas ganaderías, a causa de la propia forma de introducción pecuaria — gradual y espontánea, precediendo en muchos casos los animales a los hombres, o brusca y conflictiva, al utilizarse la ganadería como un recurso más para la guerra- y como consecuencia del distinto grado cultural en que se encontraban los pueblos americanos sometidos.

En trabajos anteriores hemos explicado cómo fue el transporte de los ganados y en qué etapas se llevó a cabo su comercio, tanto interoceánico como regional. ${ }^{1}$ En esta ocasión, nos ocuparemos de algunas particularidades de la implantación ganadera en el Nuevo Mundo, reflejando de qué forma fue pionero este proceso, a la vez que se apoyaba en las experiencias asimiladas con anterioridad en otros territorios americanos de los que partían conquistadores y colonos, centrándonos específicamente en una rama pecuaria tan importante como el cerdo ibérico.

\section{El alimento de los soldados}

En la producción y dieta agropastoral de la España del siglo XV, el puerco desempeñaba un importante papel, representando además un símbolo cultural diferenciador entre el norte cristiano y el sur musulmán, dada la aversión que sentían todos los creyentes mahometanos a este mamífero, por el veto religioso que imponía el Corán. ${ }^{2}$

Durante todo el Medioevo, la interrelación entre el cerdo y las mesnadas castellanas llegó a ser sumamente significativa. Su importancia no cambió sustancialmente en los albores de la modernidad, cumpliendo en la alimentación de la hueste americana una función muy parecida, tal y como

1 Río Moreno, Justo L. del: Guerreros y ganaderos I. Caballos y équidos españoles en la conquista y colonización de América (S.XVI). Sevilla, 1992. "El comercio caballar entre Andalucía y América y el mercado de la conquista (1492-1542)". Buenavista de Indias. núm. 1, Sevilla, 1992, páginas 27-44. "El comercio atlántico de ganados y la economía de conquista en América (1493-1542)". I Congreso de Razas Criollas. Feria Internacional Ganadera del Quinto Centenario-Zafra 92. Madrid, 1995 , en prensa.

2 Gade, Daniel W.: "The iberian pig in the Central Andes". Separata de Journal of Cultural Geography, 1989, págs. 35-49. 
confirman las narraciones de Gonzalo Fernández de Oviedo, Bernal Díaz del Castillo, Gutiérrez de Santa Clara y otros cronistas.

Su papel fue un tanto anónimo, por lo que ha sido tratado en las crónicas y en la propia historiografía americanista de forma secundaria pues, a diferencia de los caballos, no participaban en las batallas ni ofrecían prestigio a capitanes y soldados. Sin embargo, en su favor hay que apuntar que el proceso de conquista no se resolvía con una única batalla ni éste lo llevaron a cabo sólo los capitanes y soldados más prestigiosos, dependiendo su resultado en buena medida del abasto cárnico, del comer o descomer, es decir de los soldados que arreaban las piaras en el camino que seguían las huestes o establecían campamentos en la retaguardia para criar los cerdos que alimentaban a los hombres que luchaban en la vanguardia. ${ }^{3}$

Su preponderancia en la alimentación se debió a que fue la especie que primero y más se desarrolló, tanto en las Antillas como en el continente, desde Nueva España hasta Tierra Firme y Perú. Los marranos siguieron a las huestes por varias razones. Eran abundantes en las Antillas y, por tanto, muy baratos; el consumo de su carne se había generalizado entre la población española asentada en las grandes islas; en los barcos ocupaban poco espacio y su omnivorismo les permitía alimentarse con facilidad; en tierra no requerían cuidados especiales ni mucha mano de obra; podían cebarse conforme caminaban los soldados; se adaptaban a todo tipo de medios y su reproducción era sumamente pródiga. ${ }^{4}$

Se entiende así que con tocinos y cazabe se sostuvieran las huestes de Ponce de León en Puerto Rico, Esquivel en Jamaica y Velázquez en Cuba, así como las expediciones a México de Hernández de Córdoba, Grijalba, Narvaez y el propio Cortés, quien cargó más de tres mil piezas en un primer momento y grandes cantidades en fechas postreras. ${ }^{5}$

En las costas de Tierra Firme las trancas entraron siguiendo a las expediciones de Ojeda, Nicuesa y Vasco Núñez de Balboa -en el Darién-o a las de Federman, Alfinger y otros capitanes alemanes en las inmediaciones de Coro. A estas primeras iniciativas siguieron las de otros

3 García Martínez, Bernardo: "Introducción del ganado en Nueva España". I Congreso de Razas Criollas. Feria Internacional Ganadera del Quinto Centenario-Zafra 92. Madrid, 1995, en prensa.

4 Cobo, Bernabé: Historia del Nuevo Mundo. Madrid, 1943, cap. VII, págs. 44-46.

5 Cortés también reconocía que embarcaron "vino y vinagre, haba y garbanzo y aceite...", aunque dejaba claro que tocino y cazabe eran los alimentos preponderantes. Archivo General de Indias (en adelante AGI), Justicia, 221, núm. 1, fols. 23-24. Residencia de Hernán Cortés, probanza de descargos. 
conquistadores como Rodrigo de Bastidas en Santa Marta, Diego de Ordás y Francisco Sedeño en Paria y las de Pedro de Heredia y el licenciado Vadillo en Cartagena de Indias y el Cenú.

Con relativa frecuencia, los jefes de las huestes organizaban centros abastecedores en los territorios objeto de ocupación antes de comenzar la penetración en ellos, iniciando desde estas bases los contactos comerciales con los puntos de partida. Cortés dejó en manos de Diego de Ordás la organización en Veracruz de un centro de explotación porcina a gran escala antes de comenzar el sitio de Tenochtitlan, mientras que Francisco Pizarro hizo lo propio, primero en la isla de las Flores — pequeña ínsula de la costa pacífica donde él y sus socios criaban cerdos- y después, antes de internarse en la sierra peruana, en Túmbez. ${ }^{6}$

Alternativamente, las huestes recibían un aprovisionamiento irregular desde las Antillas o los centros de colonización más cercanos. La amplitud de este abasto dependía de la cantidad y atracción de los medios de pago de que dispusieran, siendo más continuo el comercio cuando la amortización de los bienes recibidos era en metales preciosos.

Pese a que todas las huestes llevaban determinadas cantidades de tocinos o puercos, hubo momentos de escasez o mayor demanda en los que la carne alcanzó cifras astronómicas. En el Nuevo Reino de Granada, aunque la gente de Sebastián de Benalcázar trasladó de Quito una numerosa piara, coincidiendo con el reparto del tesoro del rey Zipa, la llegada de otras huestes y la propia fundación de Cali, la carne tuvo precios fabulosos. ${ }^{7}$ Por aquellos años, fue famosa la venta en almoneda de los bienes de Cristóbal de Ayala, expendiéndose los cochinos a más de 500 pesos. El mismo Sebastián de Belalcázar adquirió de Jorge Robledo una sola puerca por 1.600 pesos, festejando después el buen suceso de la conquista con su sacrificio:

“...aún ví que la misma puerca se comió un día que se hizo un banquete, luego que llegamos a la ciudad de Cali... de los vientres de las puercas compraban, antes que nasciesen, los lechones a cien pesos y más...." ${ }^{8}$

En realidad, en la América del siglo XVI no hubo una sola hueste que no llevara entre sus acopios algunos cerdos o que no basara su alimentación

6 AGI, Indiferente General, 415, fol. 135. Capitulación firmada el 26 de julio de 1529. Tudela, José de: El legado de España a América. Madrid, 1954, págs. 731-732.

7 Pereyra, Carlos: La obra de España en América. Madrid, 1930, pág. 116.

8 Cieza de León, Pedro: Crónica del Perú. Madrid, 1985, pág. 112. 
en sus carnes. Las piaras iban en los barcos, incluso, partiendo de España y yendo a regiones alejadas de los centros de proveimiento antillanos. El mismo Pedro de Mendoza, pese a las penalidades imperantes en la fundación de Buenos Aires, no fue ajeno a esta realidad. ${ }^{9}$

Una vez que la población indígena era sometida, en breve tiempo, se iniciaba el traslado masivo desde la retaguardia y los centros productores más cercanos, importándose grandes cantidades de alimentos y ganados. Este proceso comercial perduraba mientras se mantenía una demanda lo suficientemente alta como para sufragar los altos costes del transporte y proporcionar ciertos beneficios, esto es, durante la conquista y los primeros momentos de la colonización o cuando se ponían en explotación centros mineros. El tráfico ganadero perduraba durante varios años, dependiendo de la distancia, facilidad de acceso a la región y éxito en la implantación pecuaria de las nuevas poblaciones. ${ }^{10}$

Durante los primeros años de la colonización, las trancas fueron el sostén de soldados y colonos en toda América. En las Antillas esto fue así durante más de un decenio, aconteciendo de la misma manera en Nueva España y Tierra Firme. En el Perú, casi dos décadas después de acabada la conquista, podríamos hablar de las Guerras Civiles como una contienda en la que primó el proveimiento porcino de la soldadesca tanto y más que las armas ecuestres, tal y como se percibe perfectamente en la lectura de las cartas que escribían a Gonzalo Pizarro y La Gasca los miembros de sus respectivos bandos. ${ }^{11}$ De la importancia del cerdo en la nutrición de los ejércitos daba buena cuenta Hernando Bachicao, quien informaba a Gonzalo Pizarro de sus actuaciones en materia nutritiva mientras perseguía al virrey Blasco Núñez Vela:

"En este pueblo dexo a vuestra señoría quinientos puercos para que coma, que yo voy depriesa, no comí más de ciento". ${ }^{12}$

9 Zavala, Silvio: Orígenes de la colonización en el Río de la Plata. México, 1977, páginas 514 y 546 .

10 AGI, Justicia, 293, núm. 1, ramo 1, fol. 49. Declaración de Hernando de Alcántara Botello. Colección de Documentos Inéditos de América y Oceanía (En adelante CODOIN). Madrid, 1864-1889, t. XL, pág. 67.

11 Pérez de Tudela Bueso, Juan: Documentos relativos a Don Pedro de la Gasca y a Gonzalo Pizarro. Madrid, 1964, t. I, págs. 157-158; t. II, págs. 449 y 477.

12 Ibídem, t. I, pág. 428. 


\section{Organización y difusión del porcino}

Por lo general, terminada la conquista y abierto el tráfico legal con los centros abastecedores de la retaguardia, la cabaña porcina aumentó notablemente en casi todas las fundaciones poblacionales. Allí donde el sometimiento fue rápido, distribuidas las primeras encomiendas, los antiguos soldados aprovechaban los tributos en productos agrícolas y mano de obra para explotar grandes piaras, cuya alimentación y cuidado quedaba asignado a la mano de obra encomendada. ${ }^{13}$ Por el contrario, los soldados y colonos que no obtenían tributos solicitaban de los Cabildos estancias donde tenerlas, contratando a algunos porquerizos españoles o empleando mano de obra esclava para su cuidado. ${ }^{14}$

Las primeras y más completas reglamentaciones conservadas sobre explotación de criaderos corresponden a Nueva España y fueron redactadas por iniciativa de Hernán Cortés, quien ya en sus ordenanzas de 1525 dictaba algunas medidas a imitación de la propia práctica antillana. La concesión de sitios para trancas sólo estaba permitida a los Cabildos, cediéndose una extensión de media legua a la redonda para uso exclusivo del concesionario; si éste mudaba de corral, nadie podía usarlo hasta que no hubieran transcurrido seis meses de su abandono, tiempo que se consideraba suficiente para recobrar el ganado perdido. ${ }^{15}$

Estos y otros dictámenes corroboran el interés por la cría porcina, sector que durante toda la década de 1520 tuvo en México y Panamá una alta rentabilidad, así como en el Perú y el interior de la meseta de Bogotá en la década siguiente, entre otras razones porque la demanda creció paulatinamente y no existieron otras carnes disponibles.

En cada uno de los distintos territorios americanos el precio de la carne porcina dependió de la oferta existente y ésta del desarrollo de la colonización. En las nuevas fundaciones, cuando los recursos económicos fueron insuficientes o se produjo algún levantamiento indígena, no faltaron las confiscaciones y robos para asegurar el sustento diario. ${ }^{16}$

13 Matesanz, José: "Introducción de la ganadería en Nueva España, 1521-1535". Historia Mexicana, vol. XIV, n. ${ }^{\circ} 4$, México, 1965, pág. 537.

14 Bejarano, Ignacio: Actas Capitulares de México. México, 1889, t. I, pág. 114.

15 González del Cossío, Francisco: Historia de la tenencia y explotación del campo desde la época precortesiana hasta las leyes del 6 de enero de 1915. México, 1957, t. I, págs. 215-216.

16 AGI, Justicia, 234, núm. 1, fols. 596-597v. 
Sometidos los distintos territorios, la demanda creció al amparo del incremento poblacional, de los requerimientos mineros y de las compras que se hacían para el proveimiento de distintas expediciones que partían hacia tierras más lejanas.

En Nueva España el negocio de la cría porcina parecía tan bueno que la mayor parte de los encomenderos invirtieron importantes recursos en él, teniendo como único inconveniente la inestabilidad imperante durante toda la década de 1520 en la percepción del tributo. Esta circunstancia supuso la ruina de no pocas explotaciones, malográndose ganancias de miles de pesos con la sucesión de distintas administraciones y los frecuentes cambios en la concesión de las gabelas.

Las inculpaciones y pleitos atestiguan el interés que por entonces despertaba esta cabaña entre la mayor parte de los encomenderos, pues la suspensión en el disfrute del tributo — personal y en especie — implicaba la pérdida de trabajadores indios, maíz y otras percepciones, además de la expulsión de los cerdos del término de la encomienda por el nuevo concesionario. Una explotación con 800 ó 1.000 cochinatas proporcionaba anualmente más de 1.000 pesos y esta suma era lo suficientemente respetable como para mantener los litigios en distintos tribunales durante décadas. ${ }^{17}$

Junto a la demanda de las ciudades más importantes - México, Veracruz, Panamá y Lima - el principal mercado estuvo en las minas. Habitualmente, el encomendero daba salida a sus producciones mediante su asociación con un minero que contaba con esclavos, aunque también fue frecuente que él mismo practicase la extracción de metales. Durante las décadas de 1520 y 1530 estas sociedades fueron muy comunes. Mientras tanto, favorecida por el crecimiento de las necesidades mineras y el aumento poblacional de las jóvenes fundaciones, la crianza progresó sin otro inconveniente que la inestabilidad en la percepción del tributo indígena. ${ }^{18}$

Progresivamente, los precios fueron disminuyendo hasta el estancamiento de la demanda. En el caso de México esta recesión se produjo en 1531, en gran parte por las ventas masivas que se hicieron con la llegada de la Segunda Audiencia, tras la suspensión en el disfrute de muchas encomiendas y la creación de numerosos corregimientos. Este año el mercado porcino llegó a estar tan saturado que los precios se derrumbaron totalmente, dejando de interesar su explotación. Hasta entonces, durante toda la

17 AGI, Justicia, 109, ramo 4. AGI, Justicia, 121, núm. 1, ramo 3, pieza 1.

18 Millares Carlo, Agustín: Índice y extractos de los Protocolos del Archivo de Notarías de México D. F. México, 1945, t. I, núm. 1024, pág. 233. 
década de 1520, el cerdo fue en Nueva España un medio de cambio más. De hecho, no son raros los casos de pobladores que saldaban sus compromisos económicos con la cesión de algunas cabezas. Claro que, con tal espectacular aumento, perdió valor y dejó de cumplir esta función. ${ }^{19}$

El proceso de multiplicación de la cabaña porcina se observa con claridad en la curva descendente que siguen los precios del arrelde de carne en México desde 1524 a 1541. Como puede observarse en el gráfico, de los 334 maravedíes que valía en la primera fecha, pasó a costar 20 maravedíes en 1528 y sólo 8 en 1541, es decir en los cuatro primeros años se redujo un $94,02 \%$, disminuyendo en la última fecha hasta el $2,39 \%$ de la primera cifra..$^{20}$

\section{EVOLUCIÓN DEL PRECIO DE LA CARNE EN MÉXICO}

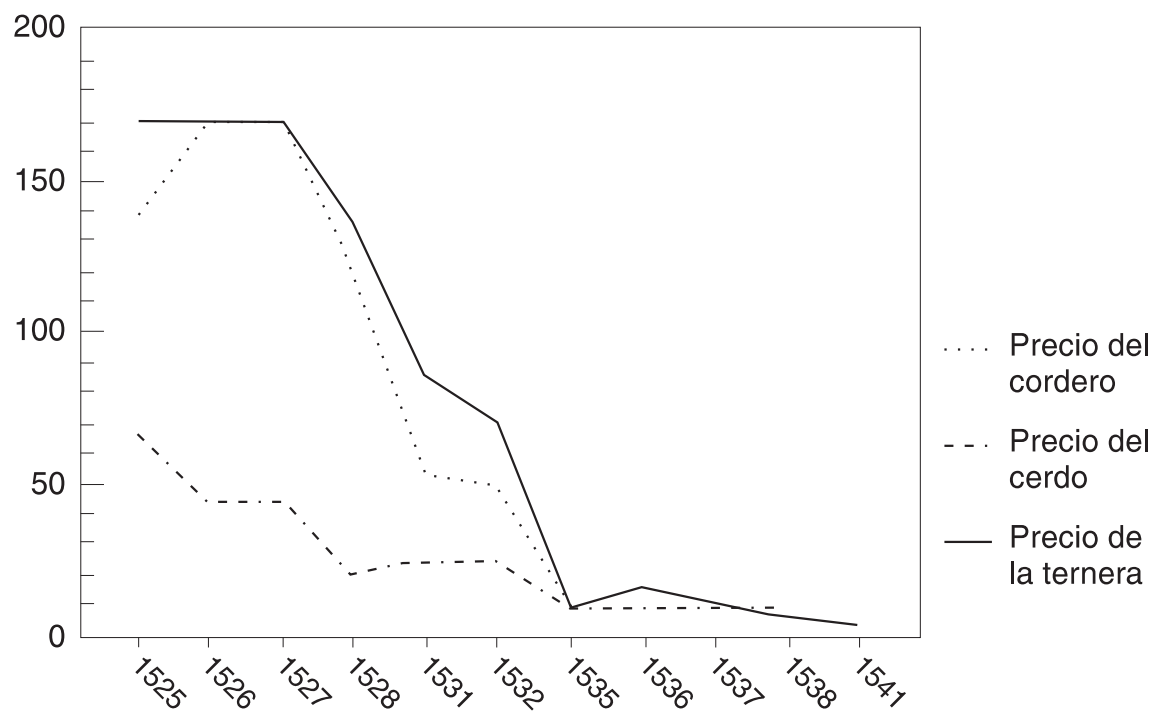

Fuente: Actas del Cabildo de México

19 Ibídem, t. I, núm. 118, pág. 54.

20 François Chevalier (La formación de los latifundios en México: Tierra y Sociedad en los siglos XVI y XVII. México, 1975, pág. 118) y José Matesanz (“Introducción...”, pág. 537) mantienen que el precio llegó a su cota más baja en 1532, costando el arrelde 25 maravedís, pero, como demostramos, ya en 1528 dicho valor era bastante inferior. 
Precios del ARRELDE DE CERdo EN MÉXICO

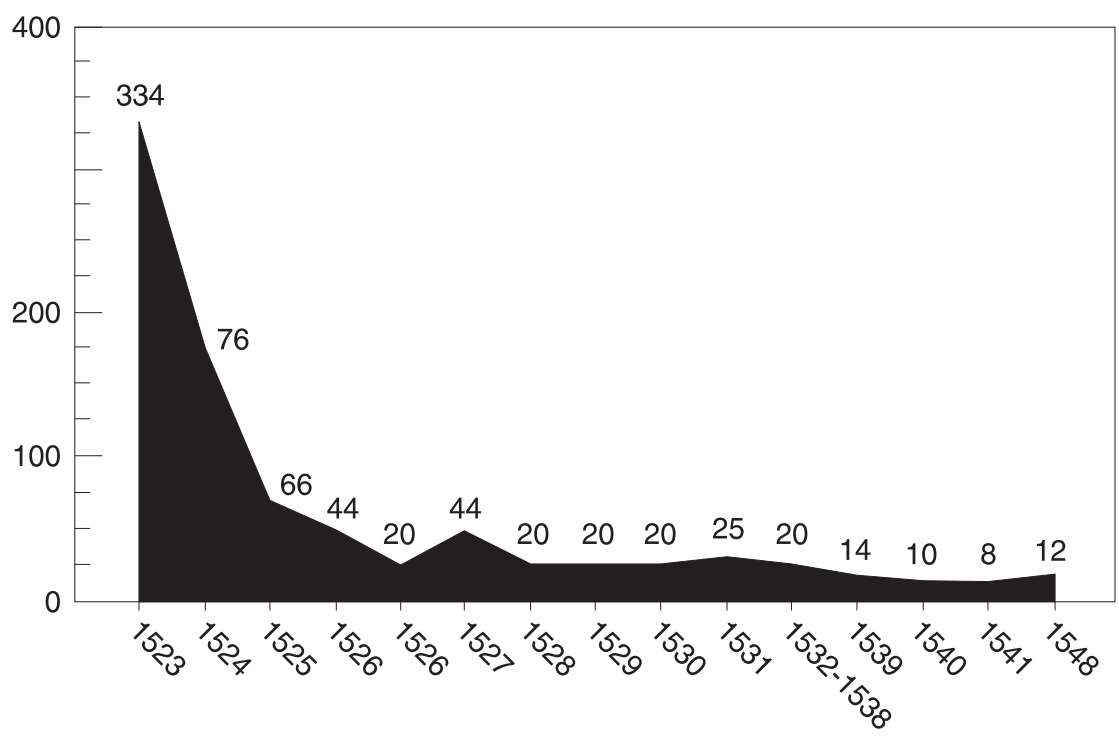

Fuente: Actas del Cabildo de México

Precios DEL ARRELDE DE CERdo EN MÉxico y LiMA

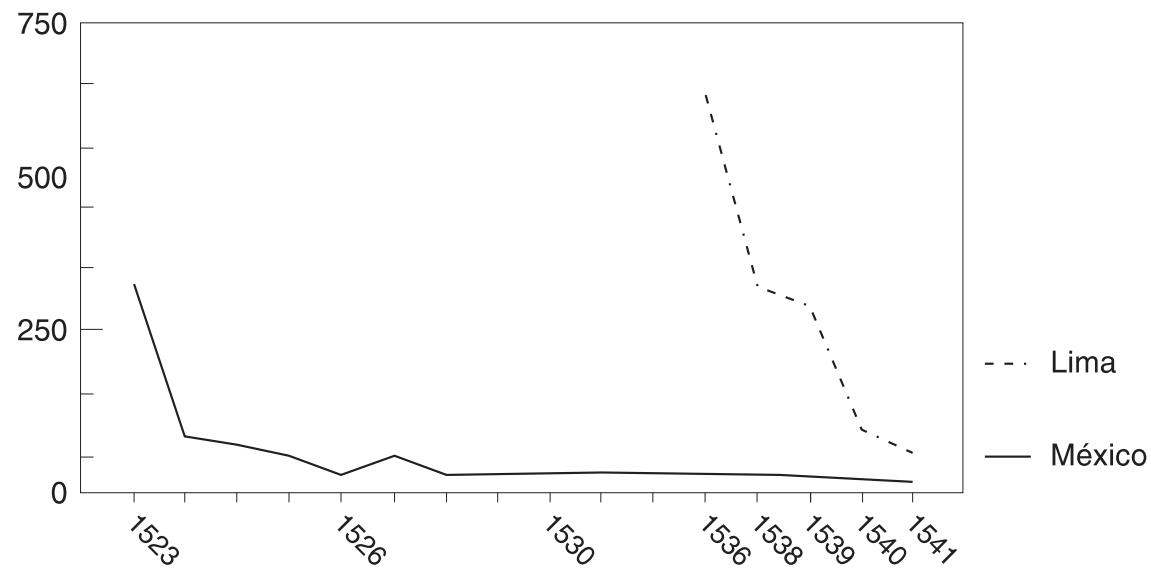

Fuente: Actas del Cabildo de México y los libros cabildos de Lima 
Cuando desaparecieron las ganancias, los ganaderos abandonaron la cría porcina, recuperándose los precios con el decrecimiento de la oferta y la reactivación de la demanda a finales de la primera mitad del siglo. En 1546 la producción era tan insuficiente que ningún obligado era capaz de encontrar carnes para proveer a la ciudad de México, mientras que tres años después la carne porcina seguía siendo tan escasa que el Cabildo no tuvo más remedio que establecer una tasa para los distintos productos comercializados. ${ }^{21}$

En los territorios dependientes de la Audiencia de los Confines los criadores de porcino también fueron los principales productores de carne durante todo el decenio de 1520, si bien la situación fue sustancialmente distinta a la novohispana, pues la demanda se mantuvo superior a la oferta durante un período mucho más prolongado. En efecto, si en 1521 Carlos I tenía que paliar la necesidad de Panamá con la donación de 1.000 cabezas, trascurrida casi una década Pedrarias Dávila solicitaba una merced parecida para las fundaciones de la vertiente pacífica nicaragüiense, mientras que Gonzalo Fernández de Oviedo hacía lo propio para Panamá. ${ }^{22}$

Durante todo el decenio siguiente el aprovisionamiento cárnico de Panamá y las restantes ciudades del istmo fue especialmente preocupante, por cuanto la oferta no aumentó sustancialmente y los precios se mantuvieron en cuotas elevadas, debido a la atracción que ejercía el Perú sobre la población y a la propia demanda de las nuevas fundaciones. Para remediar las deficiencias cárnicas, en 1537 las autoridades tuvieron que obligar a todos los encomenderos de la región a criar cierta cantidad de cochinas, conforme al número de indios que tuviesen. ${ }^{23}$ En sucesivos años, la carne se abarató, pero fue gracias a la oferta desmesurada de carne vacuna.

En Granada y León, los principales centros coloniales de Nicaragua, existía ya en la década de 1530 una importante oferta porcina que se exportaba a Panamá y Perú. Muy distinta fue la situación en la gobernación de Honduras, donde todavía en 1539 carecían aún de un número significativo de piaras. Los precios de productos básicos como la carne o el vino llegaron a ser tan altos que en comarcas de economía minera como las de

21 Bejarano, I.: Actas..., t. IV, págs. 160, 210 y 278.

22 CODOIN, t. XL, pág. 463.

23 AGI, Panamá, 335, lib. 6, fols. 129-129v. Real cédula al gobernador de Tierra Firme, Valladolid, 19 de octubre de 1537. 
Trujillo, San Pedro y Gracias a Dios, los empresarios soportaban con dificultad tantos costes. ${ }^{24}$

En el Perú, con la arribada de continuas remesas y su fácil reproducción, las disponibilidades aumentaron considerablemente. Las piaras se multiplicaron tanto que, un año después de fundada Lima, en 1536, se mataba en la ciudad un marrano diario. El precio todavía era elevado, pues cada arrelde (1'820 kilogramos) costaba 675 maravedíes, si bien bajó en enero de 1538 a 337 maravedíes $(49,92 \%)$ y en abril del mismo año a 280 maravedíes $(41,48 \%)$, repitiéndose la curva de precios novohispanos durante la década de 1540 hasta las Guerras Civiles, momento en el que la tendencia decreciente de los precios se convirtió en ascendente. ${ }^{25}$

Desde finales de la década de 1530, las tierras inmediatas a las primeras fundaciones peruanas se llenaron de puercos, elaborándose en la sierra mejores tocinos y perniles que en la propia España. Las trancas no comían sino lo que encontraban en los campos, aunque, como anotaba en 1539 el obispo de Cuzco fray Vicente de Valverde, "se hacen como de bellota". ${ }^{26}$

En Quito la multiplicación fue tan desaforada que, en 1538, el Cabildo terminó por prohibir a los vecinos que tuvieran más de diez cabezas para su alimentación. ${ }^{27}$ Ciertamente, pocos años después de fenecida la conquista —en 1541—, la ciudad disponía ya de suficientes crianzas como para proporcionar a Gonzalo Pizarro los cerca de 3.000 cochinos que llevó en su expedición al País de la Canela. ${ }^{28}$

Después de las Guerras Civiles, los precios subieron como consecuencia de la alta demanda y de la inexistencia de importantes cabañas para el abastecimiento cárnico fuera de las autóctonas de llamas. A esta situación se llegó también debido a la pérdida de muchas encomiendas, a la desatención que hubo en la crianza, a la creación de nuevas poblaciones desde los focos fundacionales costeros y, sobre todo, a la puesta en explotación de Potosí y otros centros mineros. ${ }^{29}$

24 CODOIN, t. XXIV, pág. 289. Carta de Francisco de Montejo. Gracias a Dios, 1 de junio de 1539 .

25 Lee, Bertram: Libros Cabildos de Lima. Lima, 1935, t. I, págs. 102, 183, 200 y ss. Lockhart, James: El mundo hispanoperuano, 1532-1560. México, 1982, pág.190.

26 CODOIN, t. III, pág. 124. Carta del obispo de Cuzco, 20 de marzo de 1539.

27 Feyles, Gabriel: Actas capitulares de la ciudad de La Paz, 1548-1554. La Paz, 1965, t. I, pág. 358 , nota 4 .

28 López de Gómara, Francisco: Historia General de las Indias. Barcelona, 1985, t. I, pág. 207.

29 Con el levantamiento de Gonzalo Pizarro en 1545, Antonio de Solar perdió los 300 puercos que tenía en su encomienda del valle de la Barranca. AGI, Justicia, 402, fol. 1000. 
Merced a todos estos factores, los precios casi se triplicaron, pues si en 1545 un puerco mediano tenía en Lima un valor que oscilaba entre 3 y 6 pesos, siendo "bueno y escogido", en 1549 costaba —engordado con maíz- 11 y 12 castellanos, aún habiendo en los términos de Lima más de 14.000 cabezas. $^{30}$

\section{Tributo y desarrollo porcino}

Finalizadas las conquistas y no existiendo aún una distribución efectiva de la mano de obra india, los capitanes de huestes se veían presionados por sus antiguos compañeros para legalizar el empleo de aborígenes encomendados en el cuidado de cerdos, tal y como aconteció en México, Panamá o Perú. ${ }^{31}$

Siguiendo la costumbre antillana, los encomenderos contrataban a un mayordomo o calpisque para que administrase la encomienda. Estos llevaban la contabilidad de la explotación, vigilaban e instruían a los porquerizos proporcionados por las comunidades y comercializaban los productos, recibiendo a cambio un sueldo o un porcentaje de las ganancias. Los emolumentos que percibían eran altos, porque no eran muchos los españoles dispuestos a desempeñar estos trabajos, lo cual prueba el hecho de que encontremos en la dirección de las encomiendas a calpisques distintos casi anualmente e, incluso, cada cuatro o cinco meses. Este esquema, que se reglamentó por primera vez en México, se repitió años después en Centroamérica, Tierra Firme y Perú.

En relación con la retribución, durante las primeras décadas del poblamiento, fue más normal que los peninsulares recibieran a cambio de su trabajo una parte concreta de los ganados criados o de las ganancias, antes que un salario. ${ }^{32}$ Los porcentajes pagados variaban de un tercio a un sexto de una o varias producciones, dependiendo del número de sectores económicos en que participasen, de las previsibles ganancias, la ubicación de la encomienda con respecto a los distintos mercados mineros y de la existencia de focos poblacionales españoles en las cercanías, incluyéndose en algunas ocasio-

30 Pérez de Tudela, J.: Documentos..., t. II, pág. 337. Relación de La Gasca al Consejo de Indias, Los Reyes, 2 de mayo de 1549.

31 González del Cossío, F.: Historia..., t. I, pág. 210.

32 AGI, Justicia, 117, núm.5, pieza 1. Declaración de Francisco Gallego. 
nes una esclava india, ciertas cantidades de vino y hasta una cabalgadura. ${ }^{33}$ Otras veces, cuando el encomendero no tenía cerdos, se asociaba para su crianza con aquellos que carecían de mano de obra y maíz. ${ }^{34}$

La contribución que solían dar los indios era también muy variable, dependiendo del número de tributarios y de la riqueza de la tierra en la que se asentaba la comunidad. En general, casi todas debían sembrar grandes sementeras de maíz, trasladar el cereal a las estancias donde estaban los marranos, almacenarlo, proporcionar porqueros y alimentarlos. Algunos pueblos, incluso, transportaban los cerdos a las minas para venderlos. ${ }^{35}$

En Nueva España, a partir de mediados de la década de 1540, como consecuencia de la tasación de los tributos, fue reduciéndose el servicio personal prestado en el cuidado y crianza de ganados. Algunas comunidades llegaron a conmutar las sementeras y trabajos personales por una contribución monetaria, aunque los cambios de parecer de los dirigentes indios fueron frecuentes, conforme convenía a los intereses del encomendero o de la comunidad. ${ }^{36}$

En las tasaciones de encomiendas de Yucatán, Guatemala, Nicaragua, El Salvador y Santa María de Comayagua los pueblos visitados después de la aplicación de las Leyes Nuevas estaban obligados a proporcionar varias personas, normalmente niños o muchachos, para cuidar los cerdos o ganados del encomendero. Por lo general, la mayor parte de los artículos de dicha normativa que regularizaban la prestación laboral o el servicio personal no eran acatados, aunque sí parece evidente que los visitadores trataron de disminuir y especificar — para impedir los abusos_ - la contribución laboral de las comunidades. ${ }^{37}$

Coincidiendo con la multiplicación del cerdo, los daños en las sementeras de los naturales se generalizaron, prohibiéndose su explotación en las tierras de encomiendas. La medida se aplicó primero en Nueva España y

33 Millares Carlo, A.: Índice..., t. I, núms. 432 y 788, págs. 120 y 191.

34 En 1525 Diego Valdés constituyó una compañía con Cristóbal Pacheco. El primero aportó 100 puercas y el segundo el pueblo indio de Ocopetayuca. Para cuidar de la tranca contrataron a Juan Bautista, quien percibía un quinto de las crías y otro quinto de todo el oro, maíz y esclavos que recogiesen en la encomienda. Ibídem, t. I, núms. 167 y 168, pág. 64.

35 Zavala, Silvio: El servicio personal de los indios en la Nueva España I. 1521-1550. México, 1984, pág. 157. Miranda, José: El tributo indígena en la Nueva España durante el siglo XVI. México, 1952, pág. 193.

36 González del Cossío, Francisco: El Libro de las Tasaciones de los pueblos de Nueva España. Siglo XVI. México, 1952, págs. 491-493 y 365.

37 AGI, Guatemala, 128. Tasación de servicios de Guatemala, Nicaragua, Yucatán y pueblos de Comayagua.

Tomo LIII, 1, 1996 
hacia 1537 en Tierra Firme, donde fue necesario limitar las explotaciones porcinas, estableciéndose un tope en el número de cabezas en función de la cantidad de indios que pagaban gabelas. ${ }^{38}$

Lamentablemente, en breve tiempo, la legislación se olvidó o se relajó su aplicación, mientras que en numerosas comarcas el remedio resultó ineficaz e insuficiente. A partir de entonces la tendencia fue prohibir a los encomenderos que tuvieran cerdos en los términos de sus tributarios, tal y como se hizo en Cartagena de Indias. ${ }^{39}$

Pero no todo fue negativo para el aborigen, pues como consecuencia de esta intervención en la cría del marrano, asistimos a una progresiva familiarización con su explotación. La comunidad de Tacubaya tenía a mediados del siglo XVI una treintena de puercas, mientras que un elevado número de sus vecinos contaba también con cerdos y gallinas. Un caso concreto era el de Mateo de Tescocoaque, quien practicaba la cría de aves y puercos para mantenerse. ${ }^{40}$

En la segunda mitad del siglo XVI, si el sector no estaba más extendido entre las poblaciones indias vecinas a México fue porque el Cabildo de la ciudad, con el afán de reducir la regatonería, había prohibido reiteradas veces que vendieran, compraran o matasen puercos. Con todo, pese a la impresión que pueda ofrecer lo anteriormente expuesto, lo cierto es que a medida que avanzó la colonización, la cría de cerdos fue generalizándose con rapidez. De hecho, hacia 1580 , su producción y consumo era muy corriente entre la mayor parte de los nativos que vivían en el centro de Nueva España. ${ }^{41}$

En Guatemala el proceso de aculturación fue más lento, existiendo también notables diferencias entre unos territorios y otros, pues mientras que en 1569 el juez visitador de Petapa tenía que adquirir determinadas cantidades de marranos para introducir la crianza en el pueblo, San Juan de Zacatepeque, encomendado al cronista Bernal Díaz del Castillo, explotaba algunos años antes una veintena de cochinatas con notable éxito. ${ }^{42}$

38 A los encomenderos Diego de Loaysa y Mateo de Monjaraz se les prohibía tener cerdos en el pueblo de Ixutla, Oaxaca. Altolaguirre y Duvale, Angel de: Gobernación Espiritual y Temporal de las Indias. Madrid, 1927, t. III, pág. 207.

39 Ídem.

40 Carrasco, Pedro: Colección de documentos inéditos sobre Coyoacán. Visita del oidor Santillán al pueblo de Coyoacán y su sujeto Tacubaya en 1553. México, 1976, pág. 31.

41 Bejarano, I.: Actas..., t. V, pág. 101. Moreno Toscano, Alejandra: Geografía económica de México (S. XVI). México, 1968, pág. 74.

42 AGI, Guatemala, 145, fol. 10v. Tasaciones de tributos de Guatemala. 
Por lo general, hasta el último tercio del siglo XVI, la mayor parte de las comunidades indígenas guatemaltecas no intervinieron activamente en la producción de carne porcina. Y esto es evidente, porque en 1572 el juez administrador de los naturales de la comarca de Santiago tenía que elaborar una pormenorizada ordenanza para promover la cría de marranos entre los indígenas, concediendo préstamos para la compra de los animales y favoreciendo el desarrollo de la actividad mediante incentivos para la venta en la capital de la gobernación. ${ }^{43}$

La introducción del cerdo en la economía india fue más rápida e intensa en aquellas regiones con poblaciones culturalmente avanzadas, esto es, entre aztecas e incas. En general, además de las facultades de la población autóctona para aceptar los nuevos elementos culturales, la difusión porcina dependió de la cercanía de la comunidad a los lugares de poblamiento españoles, del establecimiento de casas religiosas, de las medidas adoptadas por la Administración y del tipo de tributos exigidos, siendo mayor cuando más grande era la prestación personal.

\section{Poblamiento y crianza}

Fruto de la interacción entre hombres y animales, en no pocos casos las zahurdas se construyeron en las propias casas, en muchos otros los cerdos pulularon por las calles e inmediaciones de los jóvenes villorrios, conviviendo con la población india y española. Las quejas contra ellos no tardaron en surgir, ya que los colonos protestaban por el mal olor, los contactos o baños de los animales en el agua potable, la ruptura de las cañerías o acequias y el esparcimiento de sus excrementos por las poblaciones. Temerosos siempre de las epidemias, los Cabildos tuvieron que tomar medidas contra los efectos de este contacto.

En el caso novohispano, tenemos constancia - ya en una fecha tan temprana como 1525 - de distintas reglamentaciones dictadas por el Ayuntamiento de México para que sus vecinos no tuvieran puercos en la ciudad. Constantemente, los regidores mexicanos volvieron a incidir en el mismo asunto, permitiendo a los españoles que pudieran matar todos los cerdos que estuvieran sueltos por las vías públicas sin incurrir en delito. Pero esta y otras medidas por el estilo no tuvieron demasiado efecto, acce-

43 AGI, Guatemala, 45. Ítem V de las instrucciones de Francisco del Valle Marroquín, 24 de marzo de 1572 .

Tomo LIII, 1, 1996 
diendo los regidores a que los vecinos que quisieran cuidar algunos cochinos para su sustento pudieran guardarlos en sus casas. ${ }^{44}$ Naturalmente, el mandato se relajó y en sus aspectos esenciales no fue cumplido, tal y como corroboran las continuas advertencias y disposiciones dictadas al respecto en años postreros. ${ }^{45}$

En varias ocasiones los ediles mexicanos dispusieron que todos aquellos que quisieran sacar sus cerdos a comer tendrían que conducirlos al campo una hora después de salido el sol y recogerlos tras ponerse el astro, bajo pena de confiscación. Como la normativa no se cumplía, cansados de prohibir que los cochinos pasearan por la urbe, concedieron licencia para hacer zahurdas de propiedad comunal a los lados del camino de Chapultepec, aunque tampoco esta medida dio los resultados esperados. ${ }^{46}$

Durante los primeros años de colonización las ventas se realizaban en las plazas de las ciudades; en el caso de México, como éste era el centro de reunión y el olor de los excrementos era desagradable, se intentó trasladar el lugar destinado a celebrar los tratos hasta las cercanías del matadero. La medida no surtió efecto, al no desplazarse los compradores al reciente mercado, por lo que se tuvo que elegir nuevamente la plaza como lugar de feria, aunque restringiendo el horario desde las dos de la tarde hasta anochecido, evitando así el desarrollo de esta actividad durante las horas de paseo. Finalmente, cuando ya la población fue más numerosa y aumentaba el número de transacciones, no hubo otro remedio que cambiar el sitio destinado a compraventa por unos terrenos que estaban en las afueras de la ciudad, tal y como se repetiría años después en otras ciudades populosas como Panamá, Quito o Lima. ${ }^{47}$

En las poblaciones asentadas en el trópico, dado que la constante humedad y calor dificultaban la aplicación de medidas sanitarias concretas, los Regimientos y los propios gobernadores prohibieron a los españoles que tuviesen cerdos en el interior de las viviendas, debiendo permanecer a ciertas distancias del poblado. ${ }^{48}$

Las reglamentaciones son casi generales en todas las ciudades de América. En la Lima de 1536 uno de los capítulos de las ordenanzas relativos a la limpieza del casco urbano estipulaba que nadie podría tener puer-

44 Bejarano, I.: Actas..., t. I, págs. 58 y 82.

45 Fueron pregonados sendos bandos en septiembre y octubre de 1526, en enero y marzo de 1527 y en posteriores años. Ibídem, t. I, págs. 106, 108, 114, 124 y ss.

46 Ibídem, t. II, pág. 46.

47 Ibídem, t. I, págs. 158 y 171; t. II, pág. 191.

48 AGI, Justicia, 234, núm. 1, fol. 508. 
cos dentro, ni aún encerrados en las casas. La pena impuesta fue de medio peso por cada cabeza; sin embargo el castigo tuvo que ampliarse en febrero de 1537 a un peso, determinándose en julio de este mismo año la confiscación de los animales.99

Estas y otras muchas normas surtieron pocas veces los efectos esperados y las poblaciones continuaron padeciendo los males higiénicos que provocaban los marranos. Todavía en el último tercio del siglo XVI hombres y animales convivían en las mismas casas y esto en múltiples lugares, especialmente en las poblaciones nativas, tal y como se observa que ocurría en una fecha tan tardía como 1574 en la mayor parte de los poblados del partido de Trujillo (Perú), donde los indios tenían instalados numerosos chiqueros de cerdos y éstos paseaban libremente por las calles, daban mal olor y eran "muy dañosos para enfermedades". ${ }^{50}$

\section{El sector porcino en la segunda mitad del siglo XVI}

Después de medio siglo de experiencia, comprobada ya la importancia del correcto pertrechamiento de las expediciones y de la adecuada misión que en materia nutritiva cumplía el cerdo, la Corona procuró introducir ciertas claúsulas en las capitulaciones de conquista por las que obligaba a los capitanes a trasladar un determinado número de marranas y de hembras reproductoras de otras especies a las tierras de previsible ocupación. Las cantidades variaban de una docena a más de quinientas cabezas, dependiendo de la distancia a los focos de poblamiento más cercanos y de las previsibles necesidades, tal y como se observa en las capitulaciones de las principales huestes que se constituyeron en este período:

Hueste Destino Puercos trasladados

\begin{tabular}{llr}
\hline Menéndez de Avilés & Florida & 400 \\
Hernández de Serpa & Nueva Andalucía & 100 \\
Diego de Artieda & Costa Rica & 500 \\
Pedro Maraver de Silva & Nueva Extremadura & 200 \\
Juan de Villoria y Avila & Río Darién & 20 \\
Alvaro de Mendaña & Islas del Pacífico & 12 \\
\hline
\end{tabular}

49 Lee, B.: Libros..., t. I., págs. 96, 135 y 225.

50 AGI, Lima, 28, doc. núm. 63. 
En todos estos acuerdos, la Corona no dudó en incentivar la crianza, sabedora de que el progreso de ésta garantizaba el poblamiento, la disminución de los costes mineros y el incremento de los ingresos de la Real Hacienda vía diezmo y quinto del oro o plata. Se entiende así que en algunas capitulaciones para el poblamiento de las tierras más marginales se incluyeran una o varias claúsulas que garantizaban la exención de tributos por cierto número de años al primero que criase una determinada cantidad de lechones. ${ }^{51}$

En las regiones conquistadas durante la primera mitad del siglo XVI la situación de la producción porcina a lo largo de la segunda mitad de la centuria fue muy variable. Por lo general, el cerdo se consumió en mayores cantidades en el Perú y Tierra Firme que en Nueva España y Guatemala, lo cual no impedía que se produjeran en el México colonial jamones y tocinos tan famosos como los de Toluca - en el valle de Matalcingo- o en Guatemala chacinas tan excelentes como las de la región comprendida entre la Sierra de los Cuchumatanes y Totonicapa — comarca que confina con Chiapas-, donde cebaban a los cerdos con manzanas y sus carnes tenían un especial sabor. ${ }^{52}$

En Venezuela la mayor parte de las encomiendas tenían grandes cantidades de marranos, destacando en el último tercio del siglo XVI las crianzas de Burburata y Coro, si bien los cerdos pululaban por la mayor parte de las tierras existentes entre Coro y Maracapana. ${ }^{53}$

Las piaras eran numerosas en la meseta de Bogotá, así como en Popayán y otras poblaciones del sur del Nuevo Reino y norte del virreinato del Perú, como Guayaquil y Quito. En los términos de esta última población, pese a que se limitó el número de cabezas que podía tener cada vecino, hacia 1580 se censaban más de 12.000 ejemplares. ${ }^{54}$

Atendiendo a la producción, en Perú destacaban los valles costeros comprendidos entre Piura y Trujillo, donde algunos españoles tuvieron durante toda la segunda mitad de la centuria un buen negocio con las expor-

51 Cappa, Ricardo: Estudios críticos acerca de la dominación española en América. Madrid, 1915, t. III, págs. 58-59.

52 Vázquez de Espinosa, Antonio: Compendio y descripción de las Indias Occidentales. Washington, 1948, págs. 158 y 207.

53 AGI, Santo Domingo, 11, ramo 1, núm. 39.

54 Lizárraga, fray Reginaldo de: Descripción breve de toda la Tierra del Perú, Tucumán, Río de la Plata y Chile. Madrid, 1968, pág. 6. Ortigueira, fray Toribio de: Jornada del Río Marañón con todo lo acaecido en ella, y otras cosas notables dignas de ser sabidas, acaecidas en las islas occidentales. Madrid, 1968, pág. 240. 
taciones porcinas que hacían a la ciudad de los Reyes. ${ }^{55}$ Desde un punto de vista cuantitativo, en el virreinato destacaba Saña, criándose anualmente a finales de siglo en sus montes de guarangos más de 100.000 marranos, cantidad exportada a Lima y otras ciudades costeras, así como a Potosí y los restantes focos mineros, dada la gran demanda de sebo, chacinas y jabón. Cada puerco proporcionaba unos mínimos de sebo que oscilaban entre 5,7 kilogramos y 7,6 kilogramos, lo cual era una gran riqueza para Saña, dado que este producto era la principal materia prima empleada en la fabricación de las velas que alumbraban casas, iglesias y minas. ${ }^{56}$

En Chucuito (Collao) y Cochabamba la producción estaba enteramente orientada hacia Potosí, siendo los principales proveedores de tocinos y sebos del cerro. Aunque, dada la atracción que ejercía la riqueza de las minas, la mayor parte de los estancieros de Charcas producían marranos para este mercado. Por el contrario, desde una perspectiva cualitativa, atendiendo a la calidad de sus producciones, las regiones más famosas del virreinato fueron Jauja, Cuzco y el valle de Tarija, en Charcas. ${ }^{57}$

\section{Transformación y comercialización}

Los cerdos podían ser vendidos en pie, es decir vivos, pero lo habitual fue que productores y obligados los sacrificaran para comercializarlos por partes, elaborando distintos productos con un mínimo de transformación.

El tocino - acúmulo graso que se deposita en la sección subcutánea de la piel del cerdo- era sometido en el siglo XVI a un proceso de salazón para ser destinado a la alimentación, técnica que no ha variado en la actualidad. Separado en hojas de distintas porciones, que recibían el nombre de la región anatómica correspondiente (tocino de lomo, de espinazo, de papadas, etc.), se mantenía en sal durante ocho o diez días, conservándose aislado de la luz y de los insectos.

Ignoramos qué proporción tenía este producto en la alimentación de la población residente en las Antillas, pero sabemos que la carne y el tocino de cerdo eran de ingestión diaria, ya fuesen adobados, ahumados o en

55 Lizárraga, Fray R. de: Descripción..., pág. 14.

56 Cappa, R.: Estudios..., t. III, pág. 271. Relación del Huérfano. Citada por Puente y Olea, Manuel de la: Los trabajos geográficos de la Casa de Contratación. Sevilla, 1900, pág. 438.

57 Lizárraga, Fray R. de: Descripción..., págs. 67, 74, 75 y 89. Cobo, Bernabé: Historia del Nuevo Mundo. Madrid, 1943, cap. VII, págs. 44-46. 
salazón. ${ }^{58}$ El consumo era habitual incluso a lo largo de la Cuaresma y otros días de abstinencia cárnica ${ }^{59}$ Durante las dos primeras décadas de poblamiento los colonos de las cuatro grandes islas se nutrieron predominantemente con grasas porcinas, aunque también se consumían algunas gallinas y, desde finales de la primera década del siglo XVI, carneros y terneras.

En las fundaciones caribeñas, dada la constante humedad y los calores agobiantes del trópico, las calorías del tocino y otros productos porcinos eran asimiladas más facilmente por los trabajadores, casi todos esclavos, que por la población más ociosa, que sufría con frecuencia los efectos de la gota. Con el transcurso del tiempo, hubo diferencias notables en el consumo de carnes entre unas y otras Antillas. En Santo Domingo es indiscutible que, ya en la década de 1520, la mayor parte de la carne ingerida era de ternera. Parece innegable que el cerdo perdió bastante mercado y esto es más evidente a medida que nos acercamos a la década de 1530. En las restantes islas este fenómeno se retrasó un decenio e, incluso, en Cuba, si damos la razón a Leví Marrero, no apareció. Durante los años de 1520-1530 la población cubana prefirió el cerdo, porque era más abundante y barato que el vacuno, se conservaba mejor y su grasa podía reemplazar al aceite europeo. ${ }^{60}$

De cualquier forma, una cosa es clara: si exceptuamos el azúcar y sus derivados, el tocino, junto a los tasajos de cerdo y ternera, fue el producto alimenticio más importante en el comercio exterior antillano. Esta preponderancia en la dieta se debía a que, además de nutrirse con él la población autóctona, constituyó el elemento básico de la alimentación de las huestes y de aquellos que retornaban a España en las flotas.

En Pánuco, Nueva España y Guatemala la carne y el tocino de cerdo fueron consumidos mayoritariamente hasta principios de la década de 1530, momentos en los que decayó la producción por el abaratamiento de los precios que siguió al aumento de la oferta y a la diversificaciòn de la demanda. Entre los vecinos, además de las habituales compras en las carnicerías, fue costumbre que aquellos que tenían piaras de puercos, los encomenderos, matasen uno cada cierto tiempo. Esta era la llamada "matanza", practicada a la usanza española, empleándose la invitación —entre los más allegados - para participar en la fiesta y festín cárnico, así como el regalo

58 Altolaguirre, A.: Gobernación..., t. III, pág. 185.

59 CODOIN, t. XXXII, pág. 213.

60 Marrero, Leví: Cuba: Economía y Sociedad. Madrid, 1974, t. I, pág. 95. 
de algunas partes del animal a modo de presente. ${ }^{61}$ Estos sacrificios eran muy frecuentes, porque con cien o doscientos kilogramos de carne salada en casa una familia podía alimentarse durante meses.

En relación con la elaboración de chacinas, en las Antillas contamos con un único dato, aunque en fecha muy temprana, en la década de $1510 .{ }^{62}$ En México se vendían durante el decenio de 1540 una importante cantidad de morcillas y longanizas. Con todo, el mayor desarrollo del arte de la chacinería colonial, generalizado luego en España con la gran variedad de embutidos adobados con pimentón, se produjo en el alto, seco y frío altiplano peruano, cercano a los valles costeros donde era cultivado el ají. ${ }^{63} \mathrm{Las}$ primeras referencias de ventas de longanizas en Perú las hemos encontrado en la Lima de 1549, pero a finales del siglo este tipo de conserva estaba muy extendida, tal y como corrobora el padre Cobo, quien manifiesta que una vez sacada toda la manteca del cerdo, con el magro y perniles se hacían chorizos, morcillas y otros adobos. ${ }^{64}$

Además de la salazón y el embutido, existía también otro método de conservación, asando la carne en barbacoas, aunque este procedimiento sólo mantenía el alimento en buenas condiciones durante un corto número de días. ${ }^{65}$ Los indios también conocían el ahumado, siendo practicado en las Antillas por los tainos cuando se familiarizaron con los cerdos. ${ }^{66}$

La manteca del cerdo, grasa extraida de determinados depósitos adiposos, tenía varias categorías según su origen: la de pella, porción que cubre el riñón, es la de mayor calidad; le sigue la "tela de la barriga" o epiplón, extenso pliegue adherido al estómago y otras vísceras; por último, el "entresijo", trozo mesenterio depositado en los alrededores del intestino. ${ }^{67}$

Por el alto coste del aceite, tocinos y mantecas eran derretidos en América para utilizarse en el cocinado de alimentos y fabricación de jabón.

61 En 1527 Pedro Gentil invitaba a Melchor Rodríguez a comer con él un cuarto delantero del cerdo que había sacrificado. Por entonces, su amigo Francisco Bravo se quejó "porque no le había invitado del puerco que había muerto”, mientras que Francisco Crespo increpaba a Gentil "¿por qué no me enviaste del puerco que mataste anoche?". AGI, Justicia, 234, núm. 1, fols. 596-597v.

62 Tanodi, Aurelio: Documentos de la Real Hacienda de Puerto Rico. Buenos Aires, 1975, pág. 45 .

63 Tudela, J.: El legado..., pág. 733.

64 Lee, B.: Libros..., t. III, lib. XL, págs. 136-137. Cobo, B.: Historia ..., cap. VII, págs. 44-46.

65 Ídem.

66 Fernández de Oviedo, Gonzalo: Historia General y Natural de las Indias. Madrid, 1959, lib. LVI, cap. LI, págs. 22-223.

67 Ministerio de Agricultura, Pesca y Alimentación: Una imagen de calidad. Los productos del cerdo ibérico. Madrid, 1984, pág. 112. 
La manteca se preparaba recurriendo a la fusión mediante calor, colándose (para separar los chicharrones) y envasándose en recipientes conforme iba fundiéndose. ${ }^{68}$

Esta grasa tenía múltiples usos, siendo muy apreciada para la elaboración de dulces y postres como tortas de chicharrones, mantecados y hojaldres. ${ }^{69}$ En la sierra peruana la utilizaban para curar una sarna llamada "caracha", muy frecuente entre las llamas, untándola sobre la herida espolvoreada con azufre. ${ }^{70}$

En el México de la década de 1520 la manteca era tan importante o más que la carne, teniendo una mayor demanda, tal y como evidencia la evoluciòn que siguió su precio, lo cual se entiende teniendo en cuenta la notable necesidad que por entonces había de aceites para cocinar o fabricar jabón y el uso sustitutivo que tenía dicha grasa. ${ }^{71} \mathrm{Su}$ valor fue reduciéndose poco a poco, pero en menor porcentaje que la carne, aunque con muchas más alteraciones. Los Cabildos reglamentaron los precios de aquellas porciones que se vendían derretidas y al natural, prohibiéndose su fundición ya en fechas tempranas para impedir que se mezclara con adiposidades de inferior calidad en detrimento de los consumidores. ${ }^{72}$

El gasto y valor de tan importante producto dependió en buena medida de las disponibilidades de cerdos. En el México de 1544 tenía que proveerse que no valiera más que la carne, pues existía una mayor demanda. ${ }^{73}$ En Lima, a principios de la segunda mitad del siglo, la situación era muy semejante, regulándose el precio de la manteca —-"de empella sin mystura de otra grosura ni unto"- también a cuantías superiores que las de la propia carne. ${ }^{74}$

Otro de los productos del puerco era el llamado "unto". El consumo de este tipo de grasa era muy general entre la población novohispana, tanto que el regimiento de México reglamentó su venta, para que no fuera expendida a ojo ni en recipientes, pues los carniceros echaban en la parte baja de éstos las grasas mal derretidas. El precio, hasta 1530, superó con mucho al de la carne, vendiéndose — sin manipular — a más del doble, mientras que

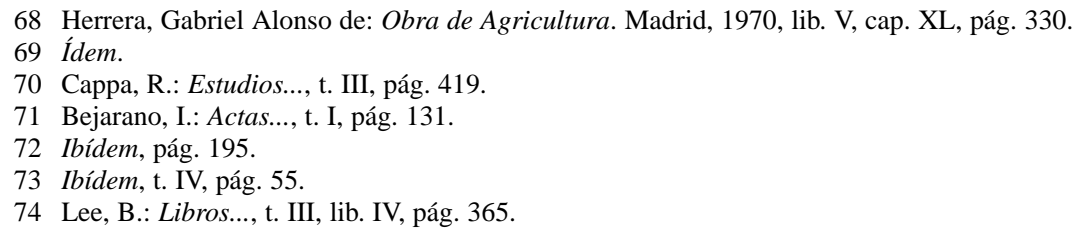


el fundido valía casi el triple. Para defender la calidad, el Ayuntamiento especificó que se expusiera en escarpias y recogiera en recipientes conforme iba desprendiéndose de la carne o tocinos..$^{75}$

El sebo, grasa de menor calificación, era usado para carenar los barcos y otras necesidades navales, así como para curar el cuero curtido. ${ }^{76}$ En Guatemala lo empleaban para zurrar todo tipo de pieles y cordobanes e, incluso, existía el oficio de zurrador o curtidor. Sin embargo, el consumo mayoritario de esta adiposidad estaba en la fabricación de velas para la iluminación de iglesias, casas y minas. La importancia de este artículo, indispensable para la vida civil y económica, se desprende de las frecuentes ordenanzas redactadas por los Cabildos americanos, preocupados todos ellos por reglamentar la producción y distribución del único combustible de origen animal que, ante la escasez y elevado valor del aceite, garantizaba una iluminación cómoda y barata. ${ }^{77}$

75 Bejarano, I.: Actas..., t. I, pág. 34.

76 En 1547 Diego de Mora proporcionaba en Trujillo a Martín de Olmos, "hartos tocinos y sebos para la fragata". Pérez de Tudela, J.: Documentos..., t. I., págs. 157-158.

77 AGI, Guatemala, 41, fol. 176. Ordenanzas de Santiago de Guatemala, 1559. 